\title{
KERATOCONUS POSTICUS CIRCUMSCRIPTUS WITH INDENTATION OF THE LENS*†
}

\author{
BY \\ HARI CHARAN \\ Department of Ophthalmology, S.M.S. Medical College and Hospital, Jaipur, India
}

UNEVEN curvature of the posterior corneal surface is a rare abnormality first described by Butler (1930). On oblique illumination the cornea presents a localized opacity not very prominent, and usually situated axially.

Only about twenty cases have so far been reported. Ingram (1936), Goldsmith (1943), Leopold (1943), Wise (1944), and Greene (1945) did not mention any associated abnormality of the curvature of the lens. Mann (1957) reported two cases of umbilication of the posterior lenticular surface. Livant (1956) reported a case of bilateral indentation of the anterior surfaces of both cornea and lens. The following case appears to be unique.

\section{Case Report}

A 22-year-old man had had poor sight in the right eye as long as he could remember. There was no history of trauma or recurrent soreness and nothing of significance in his past history. 4 years before he had been advised that his vision would always remain impaired because of "scarring of the right eye".

Examination.-The visual acuity was 6/60 in the right eye and 6/5 in the left.

Oblique illumination showed an irregular corneal opacity about $2 \mathrm{~mm}$. in diameter situated immediately below the centre of the cornea in the right eye.

Retinoscopy showed an abnormal scissor-like reflex in the right eye. Slit-lamp examination of the right eye showed the anterior surface of the cornea to be normal, but in the posterior surface there was a localized increase in curvature, corresponding to the opacity seen on oblique illumination. The substantia propria had an opacity corresponding to the concavity of the posterior corneal surface. The rest of the cornea was normal with no pigmentary deposits. The anterior chamber, iris, and pupil were normal, with no evidence of active or past inflammation. The lens had no opacity but the anterior surface showed a slight concavity corresponding to the corneal lesion (Figure, opposite).

General Examination.-Nothing abnormal.

Family.-An elder brother, who was a physician, was found to be normal, except for slight hypermetropia for which he wore glasses. There was no known abnormality in any member of the family.

* Received for publication September 1, 1965.

$\uparrow$ Address for reprints: as above. 


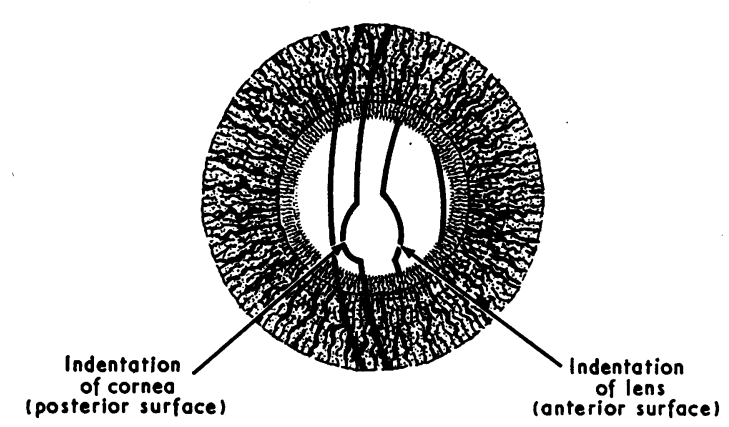

FIGURE-Diagram showing indentation of cornea and lens.

\section{Discussion}

The aetiology of this condition is unknown. The sex ratio is about equal. Jacobs (1957) considered it to result from a developmental or prenatal disturbance of Descemet's membrane and/or of the corneal endothelium. Such a disturbance in the very young could be accompanied by a resorption or failure in formation of the deeper lamellae.

In the present case, as in previous reports, there was no history of ocular injury and the condition appeared to be non-progressive.

De Rosa (1959) thought that it was caused by underdevelopment of a localized section of the corneal endothelium which provided an obstacle to the migration and normal disposition of the mesodermal cells of the corresponding area. In our case the corneal endothelium appeared to be normal.

Duke-Elder (1938) suggested that the condition arose through a delay in the separation of the lens from the surface ectoderm. Greene (1945) also thought it might be due to delayed separation of the lens from the cornea; this would explain his case which included macular corneal opacity, anterior subcapsular cataract, and a dense white opacity in the foetal nucleus. Livant (1956) explained his case on a similar basis.

In the present case the localized lesion of the anterior lens surface corresponding to the corneal lesion is highly suggestive of a developmental aberration in the separation of the lens from the cornea.

Wolter and Haney (1963) reported that histological examination revealed a general thinning of Descemet's membrane with many small breaks which were sealed by a hyaline substance deposited on the posterior surface of the membrane. In one area Descemet's membrane was split.

In our case the marked diminution of vision in the affected eye is regarded as a result of amblyopia ex anopsia due to the macular corneal opacity and to some extent uncorrected anisometropia since childhood, but in many of the reported cases the visual defect was slight. As Linksz (1950) pointed out, the greater part of the corneal refraction operates from the anterior corneal surface; this is because the difference in the refractive index of the cornea and aqueous is so small that the posterior corneal surface is relatively ineffective as a refracting surface. 
In spite of the marked thinning of the cornea, the anterior curvature remains normal and withstands the normal intra-ocular pressure.

\section{Summary}

A case of keratoconus posticus circumscriptus had an associated lenticular anomaly which is considered to be significant in establishing the aetiology of this condition.

I wish to express my thanks to Miss Veena Mathur for the illustration.

\section{REFERENCES}

BUTLER, T. H. (1930). Trans. ophthal. Soc. U.K., $50,551$.

De Rosa, C. (1959). Arch. Ottal., 63, 445.

DUKE-ELDER, S. (1938). "Text-book of Ophthalmology", 2, pp. 1281-1282.

GolDSMITH, A. J. B. (1943). Trans. ophthal. Soc. U.K., 63, 180.

GreEne, P. B. (1945). Arch. Ophthal. (Chicago), 34, 432.

INGRAM, H. V. (1936). Trans. ophthal. Soc. U.K., 56, 263.

JACOBS, H. B. (1957). Brit. J. Ophthal., 41, 31.

LeOpold, I. H. (1943). Arch. Ophthal. (Chicago), 30, 732.

LINKSz, A. (1950). "Physiology of the Eye. Vol. 1, Optics". Grune and Stratton, New York. Livant, S. (1956). A.M.A. Arch. Ophthal., 55, 681.

MANN, I. (1957). "Developmental Abnormalities of the Eye", 2nd ed., p. 311. B.M.A., London. Wolter, J. R., and Haney, W. P. (1963). Arch. Ophthal. (Chicago), 69, 357.

WISE, G. (1944). Amer. J. Ophthal., 27, 1406. 